\title{
Midwives' Professional Satisfaction and the Quality of Obstetric Care in Developing Country
}

\author{
Adama Faye $^{1 *}$, Pierre Fournier ${ }^{2}$, Alexandre Dumont ${ }^{3}$ \\ ${ }^{1}$ Institute of Health and Development, Cheikh Anta Diop University, Dakar, Sénégal \\ ${ }^{2}$ University of Montreal Hospital Research Center (CRCHUM), University of Montreal, Montreal, Canada \\ ${ }^{3}$ Institute of Research for Development, UMR, 216, University Paris Descartes, Sorbonne Paris City, Paris, France \\ Email: *adama.faye@ucad.edu.sn
}

How to cite this paper: Faye, A., Fournier, P. and Dumont, A. (2017) Midwives' Professional Satisfaction and the Quality of Obstetric Care in Developing Country. Open Journal of Obstetrics and Gynecology, 7, 95106.

http://dx.doi.org/10.4236/ojog.2017.71011

Received: November 28, 2016

Accepted: January 8, 2017

Published: January 11, 2017

Copyright ( 2017 by authors and Scientific Research Publishing Inc. This work is licensed under the Creative Commons Attribution International License (CC BY 4.0).

http://creativecommons.org/licenses/by/4.0/

cc) (i) Open Access

\begin{abstract}
Introduction: In Africa, poor working conditions affect the motivation of health care providers. The objective is to study midwives' professional satisfaction on the technical quality of emergency obstetric care in Senegal. Material and Methods: This was a prospective study of 16 hospitals in Senegal. The job satisfaction of midwives was measured during a personal interview. The instrument used was validated in Senegal and Mali. Other data collected relate to professional and institutional characteristics. A treatment observation grid was used to measure the quality of obstetric care in labour wards. Mixed-model linear regression was used to estimate the effect of satisfaction on the quality of obstetric care. Results: A total of 65 midwives were interviewed and 325 patients observed. The average quality score was $8.7 \pm 1.7$. The satisfaction scores ranged from $42.2 \pm 17.4$ (salary) to $76.7 \pm 12.1$ (morale satisfaction). A positive and significant correlation was found between quality of care and management $(\mathrm{cc}=0.56)$, remuneration $(\mathrm{cc}=0.40)$, task $(\mathrm{cc}=0.32)$, workload $(\mathrm{cc}=$ $0.24)$ and training $(c c=0.29)$. The linear mixed model shows that salary $(\beta=0.40)$, continuing education $(\beta=0.17)$ and management style $(\beta=0.42)$ improved the quality of care. Association between moral satisfaction and quality care was negative $(\beta=-0.53)$. Conclusion: The satisfaction of health professionals is a major determinant of the quality of obstetric care. Its inclusion in the fight against mortality has become imperative in developing.
\end{abstract}

\section{Keywords}

Motivation, Satisfaction, Quality Care, Midwives, Senegal

\section{Introduction}

Maternal mortality is a major public health problem in sub-Saharan Africa (SSA) where 
$50 \%$ of deaths occur. Most maternal deaths are preventable but difficult to predict because they can occur in any pregnant woman. About $60 \%$ of deaths occur within 48 hours of delivery [1]. According to the latest MDG report, hemorrhage (35\%) and hypertension (17\%) are the main causes of maternal deaths in low- and middle-income countries (LMIC). The orientation of programs towards improving intra-partum care would significantly reduce maternal mortality [2].

Two major strategies are recommended for the reduction of maternal mortality: skilled staff in childbirth health facilities and timely access to emergency maternal obstetric care (EmOC) in cases of complications [3]. In sub-Saharan Africa, the quality of obstetric care varies greatly [4]. Two main factors influence the quality of care in these countries: the availability of qualified personnel and the performance of health personnel. According to the report on global development, the MDGs cannot be achieved without substantial improvement in human resources. It is estimated that Africa needs about one million doctors, nurses and midwives to provide the basic services needed to achieve the MDGs [5]. Consequently, care is often provided by unqualified personnel, and this affects quality.

The effect of staff lack of knowledge and skill on the qualityof care was confirmed in a study conducted in Cameroon, Ivory Coast, Mauritania, Niger, Senegal and Mali [6] [7]. Recognising the signs of severity depends on professional trainingand experience [8]. The ability to recognize an obstetric emergency is related to the qualification of the personnel. In a study conducted in Senegal on morbidity and thequalifications of personnel involved, Dumont et al. [9] showed that recognition of severemorbidity was largely linked to the skill levels of the obstetrician. Similarly, the availability of adequate working equipment and materials plays an important role, especially in developing countries where essential apparatus may not be present [10] [11].

In recent years, although significant progress has been made regarding the availability of EmOC services, the availability and quality of these services remain a challenge for health systems in most SSA countries. Indeed, the proportion of women who benefited from the assistance of a skilled attendant during childbirth has little increased in countries with limited resources. In Senegal, it increased from $53 \%$ to $55 \%$ between 2005 and 2011 [12]. Thus, research has focused on other factors that could influence the retention and motivation of qualified personnel in health facilities to improve the performance of obstetric services. Motivation has effects on the behaviour of the individual and the organisation of service [13] which can affect the quality of care for patients. Job satisfaction is a major determinant of work motivation and it has been the subject of several studies in the context of SSA countries.

It may be the cause of delays and absenteeism [13]. The inability to conduct an examination correctly, burn-out and the desire to leave the job were also noted [13] [14]. Dissatisfied staff are less courteous and tend to communicate less or poorly with patients. Trust and continuity of care for patients were related to physician satisfaction [15]. The satisfaction of nurses is positively related to the management of pain, information on care, courtesy to the patient and family [16]. Several studies have shown a correlation between the level of interaction between doctors and paramedical staff (nurses) and mortality, medical errors and the length of hospital stays [17]. 
Quality is a complex concept that can be approached from several angles. It may be seen as a feature of health services [18]. Thus, it can be assessed in terms of good or bad [19]. It may also reflect the degree of realisation of a concept and so can be defined as "the extent towhich services for individuals and populations increase the likelihood of desired health outcomes and are consistent with current professional knowledge" [20]. Improving the qualityof care reduces maternal mortality [21].

However, to date few studies have examined the effect of professional satisfaction on the quality of care in Africa. A questionnaire was developed and validated to measure the degree of job satisfaction in obstetric services in Senegal and Mali [22]. This work aims to study the effect of midwives' job satisfaction on the technical quality of emergency obstetric care in Senegal.

\section{Method}

We conducted a cross-sectional study to measure satisfaction among midwives working inreferral hospitals in Senegal, then a cohort study was designed to assess intra-partum quality care. The study was conducted in Senegal in health facilities selected for the QUARITE trial which ran from 2007 to 2011 [23]. The study is registred on the following number: ISTCTN4690658. The QUARITE project received approval from the Ethics Committee of Research of the University Hospital of Sainte Justine (No. 2425 protocol).

All public hospitals with a maternity ward with more than 800 births a year and a functionaloperating theatre were eligible. National and teaching hospitals in Dakar, where the volumeof activity was large, were excluded from the study because many midwives worked together in the labour ward. Under these conditions, a patient could be attended by several midwives, making it difficult to measure quality of a single caregiver.

The study included midwives working in maternity and who consented to participate insatisfaction surveys and to be observed at work. The first seven women in labour whosedelivery was managed by the participating midwives were included in chronological order ofadmission. Patients who gave birth by Caesarean section or forceps delivery or vacuum wereexcluded to ensure continuity of care by the participating midwife from the start to theimmediate post-partum period ( 2 two hours after birth).

The endpoint result was the quality score. The expected level of correlation between thescores of satisfaction and quality score was 0.6. We assumed that midwives practising in the same hospital are highly correlated (ICC $=0.5$ expected). Taking into account the cluster effect, we estimated that 365 patients (five patients per midwife and 65 midwives) would highlight a correlation of 0.6 with a power of $80 \%$ and a bilateral alpha 0.05 .

A observational grid (Grille d'Observation des Soins Obstétricaux, GRIOS) was developed based on the standards and procedures used in Senegal and the recommendations for clinical practice of the International Federation of Gynecology and Obstetrics for assessingthe quality of care. The quality assessment concerns the monitoring, the work and delivery inthe delivery room, including care in the immediate postpartum period. We selected 12 criteria of care quality: six criteria for the monitoring of the 
patient and fetus during the active phaseof labor and six criteria for the prevention of postpartum haemorrhage and monitoring ofmother and newborn. Each criterion was measured by direct observation by a traine devaluator. This scale of measurement is reliable, the agreement between two independent evaluators is good [24].

The evaluator observed the midwife and patient throughout labor, delivery and two hours after birth. Each of the 12 quality criteria was measured during the observation period and recorded on the GRIOS sheet. The participating midwife, although informed in advance of the study's objectives, did not know on which day nor on which items of care the quality assessment would take place. The first two patients were not included in the study to reduce the Hawthorne effect. The evaluator also collected information about patient: age, parity, number of prenatal care episodes, treatments received and maternal and newborn health after delivery from medical record.

The satisfaction of midwives was evaluated using a standardised questionnaire including 24 items covering eight dimensions: remuneration, working environment, continuing training, workload, tasks, management, moral satisfaction and stability. This questionnaire included closed response questions and Likert-type five response level questions (5. very satisfied, 4. satisfied, 3. moderately satisfied, 2. dissatisfied, 1. very dissatisfied). This tool, created from theinstruments "Measure of Job Satisfaction" (MJS) [25] and "Job Descriptive Index" (JDI) [26] was validated on a sample of 937 care providers who worked in reproductive health facilities inMali and Senegal. It has been shown to have good validity and satisfactory reliability [22]. The questionnaire also included some questions about midwives' characteristics such as age, seniority in the profession and in the facility, level of education, trade union membership and marital status. Workplace accessibility was measured by a variable combining distance between the workplace and place of residence and the most commonly used means of transport.

Professional aspects were evaluated according to the following for factors: geographical situation of the hospital, type of institution, volume of activity and availability of human and material resources. The availability of services at each facility was assessed by the adapted version of the complexity index developed by WHO for African countries [27].

The quality score was obtained by summing the six criteria for monitoring the patient and foetus during the active phase of labour and six criteria for the prevention of postpartum haemorrhage and monitoring of mother and newborn (maximum 12 and minimum 0). Foreach dimension of the job satisfaction score, we summed item scores weighted by their loadings. Because the number of items differed depending on the dimensions, a standardisation was carried out. This resulted in satisfaction scores range from $0 \%$ to $100 \%$. First, we performed a Pearson correlation test between the quality score and the continuous variables (satisfaction score and score complexity index). For binary variables, we identified all other variables (institutional, the midwife or the patient) significantly associated $(p<0.05)$ with the quality score using Student's $t$-test.

Then a multilevel analysis was conducted from a generalized linear mixed model that took into account the cluster effect. The first level variables consisted of those collected from the mother and were introduced one by one. Then data concerning the midwife 
and the institution were introduced. Stepwise regression using backward elimination was used tobuild the final model. Variables that did not improve the model were removed one by one. The likelihood ratio test was used to compare nested models. The robustness of the model was examined by removing variables one by one (leave-oneout) and applying the model. Thelme 4 Package software $\mathrm{R}$ was used to make the mixed model.

\section{Results}

The flow chart of the study is presented in Figure 1. Of the 24 hospitals enrolled in the QUARITE trial in Senegal, 18 district or regional hospitals outside the capital were included inthe study. Two Dakar district hospitals and four national or academic hospitals were excluded.

Four others did not agree to participate. In total, the study involved 16 health facilities. These structures are in the intermediate and peripheral levels of the health pyramid.

In the 16 participating hospitals, 65 midwives were included in the quality observational study.

The number of observed midwives ranged between two and five depending on the size of the facility. For each midwife, seven intra-partum care episodes corresponding to seven patients were observed. Only the last five patients were included in the quality assessment, to limit the Hawthorne effect. In total, 325 patients were included in the analysis.

In the 16 hospitals of the study, half of which came from the regional level and the other half of the district level. The average total complexity score (eight categories) was 71.5 and the average business volume was 129 deliveries annually per midwife (Table 1).

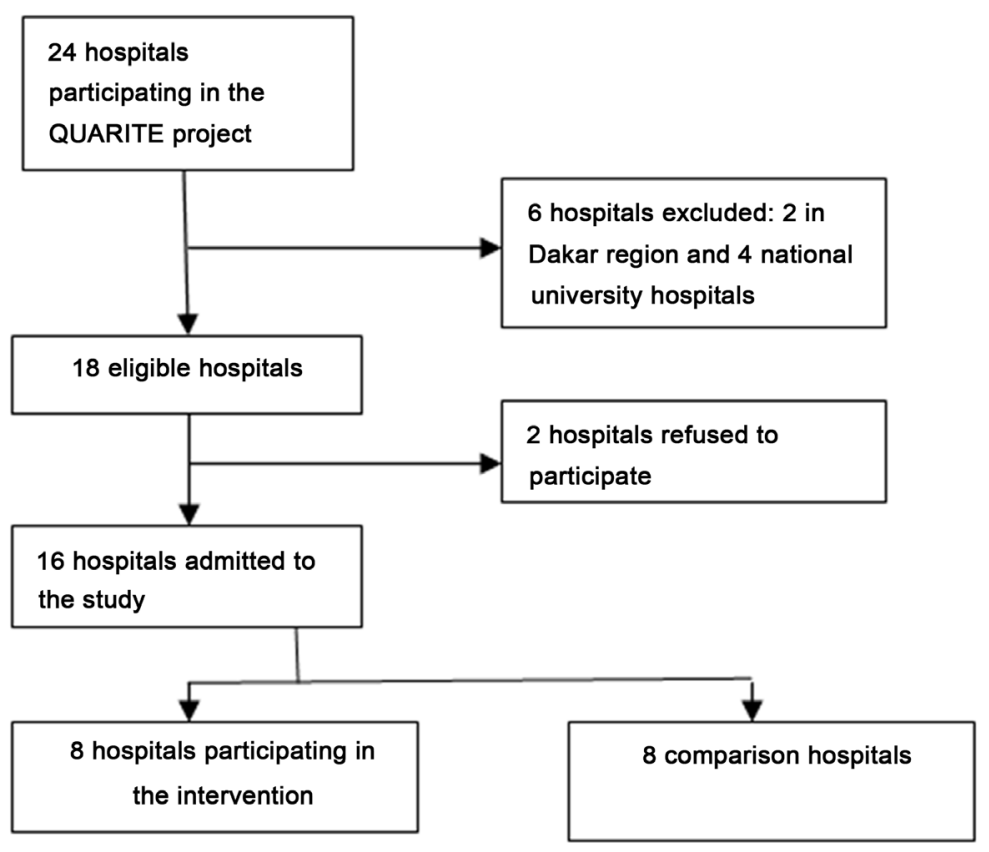

Figure 1. Flow chart of selection of participating facilities. 
Table 1. Characteristics of facilities $(\mathrm{N}=16)$.

\begin{tabular}{|c|c|c|}
\hline & $\mathrm{N}$ & $\%$ \\
\hline \multicolumn{3}{|l|}{ Facility } \\
\hline Regional & 8 & 50 \\
\hline District & 8 & 50 \\
\hline \multicolumn{3}{|l|}{ Intervention } \\
\hline Yes & 8 & 50 \\
\hline No & 8 & 50 \\
\hline \multicolumn{3}{|c|}{ Score for basic services } \\
\hline Mean (sd) & $7.9(0.2)$ & \\
\hline \multicolumn{3}{|c|}{ Score for essential services } \\
\hline Mean (sd) & $16.4(3.9)$ & \\
\hline \multicolumn{3}{|c|}{ Laboratory based screening examinations } \\
\hline Mean (sd) & $8.3(1.3)$ & \\
\hline \multicolumn{3}{|c|}{ Reanimation resources } \\
\hline Mean (sd) & $5.1(1.5)$ & \\
\hline \multicolumn{3}{|c|}{ Essential obstetric care } \\
\hline Mean (sd) & $10.6(2.3)$ & \\
\hline \multicolumn{3}{|c|}{ Intra-partum care } \\
\hline Mean (sd) & $8.8(1.5)$ & \\
\hline \multicolumn{3}{|c|}{ Human resources } \\
\hline Mean (sd) & $9.0(3.8)$ & \\
\hline \multicolumn{3}{|c|}{ Protocol for continuing education } \\
\hline Mean (sd) & $6.7(1.7)$ & \\
\hline \multicolumn{3}{|c|}{ Equipement total } \\
\hline Mean (sd) & $71.5(10.6)$ & \\
\hline \multicolumn{3}{|c|}{ Births per midwife } \\
\hline Mean (sd) & $129.4(109.3)$ & \\
\hline
\end{tabular}

The midwives were attached to regional level facilities in $56.9 \%$ of cases. Their average age was $33.7( \pm 7.0)$, years and their seniority in the profession was on average 7.1 years. More than half had reached the second stage $(55.4 \%)$ and $70.8 \%$ were married. More than half of the midwives interviewed were employees and $63.1 \%$ were unionised.

Most patients (57.0\%) attended regional level facilities. Their average age of the patients was $23.3( \pm 6.3)$. Primiparas made up $38.0 \%$ and $38.0 \%$ had achieved 4 antenatal care (ANC) and more. Still births occurred in $3.0 \%$ of cases.

The obstetric care quality score for midwives averaged (8.7/12). The highest satisfaction scores related to the following dimensions: moral satisfaction $(76.7 \pm 12.1)$, the task $(65.9 \pm 15.5)$ and stability $(61.4 \pm 20.6)$. Satisfaction was average for the continuing training andmanagement and low for workload and salary. Table 2 shows the 
Table 2. Correlation matrix for quality of care and the dimensions of satisfaction.

\begin{tabular}{cccc}
\hline Variable & Mean & sd & Correlation \\
\hline Quality of care $(\max =12)$ & 8.7 & 1.7 & \\
Satisfaction & & & \\
Salary \& benefits & 42.2 & 17.4 & $0.40^{\star}$ \\
Work environment & 47.6 & 22.1 & 0.10 \\
Workload & 47.2 & 20.5 & $0.24^{\star}$ \\
Task & 65.9 & 15.5 & $0.32^{\star}$ \\
Continuing education & 55.7 & 20.6 & $0.29^{\star}$ \\
Management style & 50.0 & 21.4 & $0.56^{\star}$ \\
Moral satisfaction & 76.7 & 12.1 & $-0.30^{*}$ \\
Job stability & 61.4 & 20.6 & $0.15^{\star}$ \\
\hline
\end{tabular}

${ }^{*} p<0.05$.

correlation matrix for quality of care and the dimensions of satisfaction. The highest correlation coefficient concerned the management dimension of satisfaction $(\mathrm{R}=0.56$; $p<0.05)$. Positive and significant correlations were also noted with "salary", "task", "workload" and "continuing education" (Table 2).

Table 3 shows the results of the mixed model. After adjustment for contextual variables, satisfaction with management and salary are the two factors most strongly correlated with the quality of care. An increase of 10 points in the satisfaction score on these two dimensions leads to an increase of 4 points in the of quality of obstetric care score. Satisfaction with training also remained correlated with quality of care after adjustment $(p<0.05)$. An increase of 10 points in this dimension resulted in an increase of two points in the quality score. Moral satisfaction, however, was negatively correlated with quality of care. Midwives who were satisfied with their work seemed to provide lower quality care. The scores for satisfaction with workload, tools, task and stability were not associated with quality of care after adjustment.

\section{Discussion}

The results of our study show an average quality score in the provision of obstetric and neonatal care by midwives in Senegal. These results are consistent with the literature on the subject. Poor health services performance was noted in several countries in Africa [4] [28]. This situation can be explained by the low level of motivation of care providers. The results of our study show that the care providers most satisfied with the financial and management aspects of their work provided higher quality care. Several studies have shown the effect of the financial remuneration on the satisfaction of care providers. In a systematic review, Willis-Shattuck et al. [29] showed that salary was the most important factor for staff motivation and retention at work in LMIC countries. Studies by Ndiaye [11] in Senegal and Pillay [30] in South Africa on the work satisfaction of doctors and nurses have found that low pay was the second most important factor after working conditions. These often vary from one profession to another. In Mali, Dieleman [31] showed that improving salary was more motivating for nurses and midwives than for doctors. 
Table 3. Quality of obstetric care and satisfaction. Linear mixed model. Results of multivariate analysis (final adjusted model using included variables).

\begin{tabular}{cccc}
\hline Factor & $\beta$ estimate & se & IC95\% \\
\hline Salary \& benefits & 0.40 & 0.04 & {$[0.32-0.47]^{\star}$} \\
Work environment & -0.05 & 0.04 & {$[-0.12-0.13]$} \\
Workload & -0.02 & 0.04 & {$[-0.98-0.06]$} \\
Task & 0.03 & 0.06 & {$[-0.09-0.15]$} \\
Continuing education & 0.17 & 0.05 & {$[0.07-0.27]^{*}$} \\
Management style & 0.42 & 0.04 & {$[0.34-0.49]^{*}$} \\
Job stability & 0.001 & 0.04 & {$[-0.07-0.07]$} \\
Moral satisfaction & -0.53 & 0.07 & {$[-0.39--0.66]^{\star}$} \\
Intervention & 0.12 & 0.59 & {$[-1.04-1.27]$} \\
Essential obstetric care & -0.11 & 0.23 & {$[-0.56-0.34]$} \\
Intrapartum care & 0.16 & 0.24 & {$[-0.31-1.63]$} \\
Total equipement & -0.02 & 0.04 & {$[-0.09-0.05]$} \\
Age & 0.04 & 0.01 & {$[0.02-0.04]$} \\
Instruction & 0.27 & 0.13 & {$[0.01-0.52]$} \\
Management position & 0.91 & 0.24 & {$[0.44-1.8]^{*}$} \\
\hline
\end{tabular}

${ }^{*} p<0.05$.

However, this improvement in the financial compensation must be accompanied by measures to ensure quality of care, as is the case in the framework of results-based financing [32]. Our results concerning the management dimension of satisfaction are also very instructive. The involvement of providers in decision making and better information on the functioning of the institution promotes professional commitment. Hence the important role of the line manager who, through good management style, can raise the efficiency of its employees [33] [34]. The inclusion of management techniques in the training curricula at medical schools is imperative. In Senegal, most health facilities are run by doctors who are often not prepared for these functions.

Satisfaction with continuing education is also a factor determining the level of quality of care in our study. By allowing the service provider to acquire new knowledge and learn new techniques, continuous training improved practice and helped to overcome work difficulties. It is also a source of motivation for the care provider. A study conducted in seven countries in Africa south of the Sahara has shown that, along with development, it was the most important factor that aided staff retention [35]. Similar results were found in Nigeria [36]. Unfortunately, in Senegal, there is no career path. Participation in training is more a choice of the head of service. Choosing staff for further training should be done on a clear basis, otherwise this can lead to frustration [11] and job dissatisfaction [37] which will have a negative impact on the quality of care. Continuing education must be adapted to the local context, because training on technologies that do not exist locally will generate frustration and thus become a factor of dissatisfaction [29]. 
The results of our study show that midwives who enhoyed job satisfaction tended to produce lower quality care. The moral satisfaction dimension was estimated by the satisfaction of the midwife with the quality of care provided and the support provided for patients, from a religious point of view. The assessment of quality of care was based on norms that reflect the average observation of acriterion, unlike a standard for judging quality based on a well-defined goal [19]. These concepts may vary from country to country and depend largely on the work environment. If, in its environment, health care is poor, the service provider may think he is providing good quality care, compared with the norm. This is often the case in sub-Saharan Africa, where the level of quality of care is often poor. The idea that one is providing good quality care can be a source of complacency that can have a negative impact on the quality of care. Unfortunately, aspects of quality are not often taken into account in the care providers training in Africa south of the Sahara [38].

Although it is recognised as an important factor in the provision of good quality care, the work environment was not an important predictor in our study. This situation may be explained by the fact that the provision of basic obstetric care does not require significant hardware resources on the one hand, and that care may be poor even if the equipment and resources are sufficient [39]. This can also be explained by the small variation of the equipment needed to perform the basic care between facilities.

Our work has some limitations. The quality measurement covers only the observable aspects of the interaction between the care provider and the woman in labour. Other aspects of the technical dimension, such as empathy and courtesy, were not measured. Since the study was carried out in intermediate and peripheral hospital facilities, the exclusion of national hospitals makes it difficult to generalise the results to all midwives. Nevertheless, all midwives are trained in the same schools, enjoy same pay, work to the same standards and protocols for providing care in childbirth; it would be reasonable to expect that the link between satisfaction and quality of care in regional and district hospitals of Senegal, would also exist among midwives at the national hospitals but at a different level.

\section{Conclusion}

In Africa, the quality of obstetric care is often implicated in the high level of maternal mortality. The results of our study show that the satisfaction of health professionals is a major determinant of the quality of obstetric care, as also are satisfaction with remuneration, continuing training and goodmanagement. These factors should be targeted in any interventions to reduce maternal mortality.

\section{Acknowledgements}

We thank all the medical and administrative staffs of all the participating centres for their valuable contributions to this study.

Adama Faye is a fellow of the Leadership Program in Population and Health funded by the Bill and Melinda Gates Foundation.

Funding for the QUARITÉ project was provided by the Canadian Institutes of Health Research (CIHR). 


\section{Authors' Contributions}

AF wrote the first draft of the manuscript with $\mathrm{PF}$ and undertook the statistical analysis. PF led the development of the study from its inception. AD have been involved in drafting the manuscript. All authors read, improved and approved the final manuscript.

\section{Key Message}

In sub-Saharan Africa, job satisfaction of care providers is low and quality care average. The satisfaction of health professionals is a major determinant of the quality of obstetric care. Taking into account the motivation of health care providers in the management of health facilities is imperative.

\section{Competing Interests}

The authors declare that they have no competing interests.

\section{References}

[1] Ozumba, B.C. and Nwogu-Ikojo, E.E. (2008) Avoidable Maternal Mortality in Enugu, Nigeria. Public Health, 122, 354-360. https://doi.org/10.1016/j.puhe.2007.04.018

[2] Nawal, M.N. (2008) An Introduction to Maternal Mortality. Reviews in Obstetrics \& Gynecology, 1, 77-81.

[3] Koblinsky, M., Matthews, Z., Hussein, J., Mavalankar, D., Mridha, M.K., et al. (2006) Maternal Survival 3: Going to Scale with Professional Skilled Care. Lancet, 368, 1377-1386. https://doi.org/10.1016/S0140-6736(06)69382-3

[4] Arifeen, S.E., Bryce, J., Gouws, E., Baqui, A.H., Black, R.E., Hoque, D.M., Chowdhury, E.K., Yunus, M., Begum, N., Akter, T. and Siddique, A. (2005) Quality of Care for Under-Fives in First-Level Health Facilities in One District of Bangladesh. Bulletin of the World Health Organization, 83, 260-267.

[5] Gerein, N., Green, A. and Pearson, S. (2006) The Implications of Shortages of Health Professionals for Maternal Health in Sub-Saharan Africa. Reproductive Health Matters, 14, 40-50. https://doi.org/10.1016/S0968-8080(06)27225-2

[6] Huchon, C., Arsenault, C., Tourigny, C., Coulibaly, A., Traor, M., Dumont, A. and Fournier, P. (2014) Obstetric Competence among Referral Healthcare Providers in Mali. International Journal of Gynecology and Obstetrics, 126, 56-59. https://doi.org/10.1016/j.ijgo.2014.01.014

[7] Traoré, M., Arsenault, C., Schoemaker-Marcotte, C., Coulibaly, A., Huchon, C., Dumont, A. and Fournier, P. (2014) Obstetric Competence among Primary Healthcare Workers in Mali. International Journal of Gynecology \& Obstetrics, 126, 50-55. https://doi.org/10.1016/j.ijgo.2014.01.012

[8] Jaffre, Y. and Prual, A. (1993) Le corps des sages-femmes, entre identité professionnelle et sociale [The Midwives Corps, between Professional and Social Identity]. Sciences Sociales et Santé, 11, 63-80. https://doi.org/10.3406/sosan.1993.1265

[9] Dumont, A., de Bernis, L., Bouillin, D., Gueye, A., Dompnier, J.-P. and Bouvier-Colle, M.-H. (2002) Morbiditématernelle et qualification du personnel de santé: Comparaison de deuxpopulations différentes du Sénégal [Maternal Morbidity and Qualification of Health Personnel: Comparison of Two Different Populations of Senegal]. Journal de Gynécologie Obstétrique et Biologie de la Reproduction, 31, 70-79.

[10] Dieleman, M., Cuong, P.V., Anh, L.V. and Martineau, T. (2003) Identifying Factors for Job 
Motivation of Rural Health Workers in North Viet Nam. Human Resources for Health, 1, 10. https://doi.org/10.1186/1478-4491-1-10

[11] Ndiaye, P., Seye, A.C., Diedhiou, A., Deme, B.S. and Tal-Dia, A. (2007) Perceptions and Motivations of Public Sector Physicians in Dakar (Senegal). Santé, 17, 223-228.

[12] Ministère de la Sante (2010) Enquête démographique et de santé au Sénégal [Demographic Health Survey, Senegal]. 210 p.

[13] Franco, M.L., Bennett, S., Kanfer, R. and Stubblebine, P. (2004) Determinants and Consequences of Health Worker Motivation in Hospitals in Jordan and Georgia. Social Science and Medicine, 58, 343-355. https://doi.org/10.1016/S0277-9536(03)00203-X

[14] Rouleau, D., Fournier, P., Philibert, A., Mbengue, B. and Dumont, A. (2012) The Effects of Midwives' Jobsatisfaction on Burnout, Intention to Quit and Turnover: A Longitudinal Study in Senegal. Human Resources for Health, 10, 9. https://doi.org/10.1186/1478-4491-10-9

[15] Siu, O. (2002) Predictors of Job Satisfaction and Absenteeism in Two Samples of Hong Kongnurses. Journal of Advanced Nursing, 40, 218-229. https://doi.org/10.1046/j.1365-2648.2002.02364.x

[16] Tzeng, H.M. and Ketefian, S. (2002) The Relationship between Nurses' Job Satisfaction and Inpatient Satisfaction: An Exploratory Study in a Taiwan Teaching Hospital. Journal of Nursing Care Quality, 16, 39-49. https://doi.org/10.1097/00001786-200201000-00005

[17] Haas, J.S., Cook, E.F., Puopolo, A.L., Burstin, H.R., Cleary, P.D. and Brennan, T.A. (2000) Is the Professional Satisfaction of General Internists Associated with Patient Satisfaction? Journal of General Internal Medicine, 15, 122-128. https://doi.org/10.1046/j.1525-1497.2000.02219.x

[18] Haddad, S., Roberge, D. and Pineault, R. (1997) Comprendre la qualité: En reconnaître la complexité [Understanding Quality: Recognizing Its Complexity]. Ruptures-Revue Transdisciplinaire en Santé, 4, 59-78.

[19] Donabedian, A. (1988) The Quality of Care. How Can It Be Assessed? JAMA, 260, 17431748. https://doi.org/10.1001/jama.1988.03410120089033

[20] Mainz, J. (2003) Defining and Classifying Clinical Indicators for Quality Improvement. International Journal for Quality in Health Care, 15, 523-530. https://doi.org/10.1093/intqhc/mzg081

[21] Dumont, A., Fournier, P., Abrahamowicz, M., Traoré, M., et al. (2013) Quality of Care, Riskmanagement, and Technology in Obstetrics to Reduce Hospital-Based Maternal Mortality in Senegal and Mali (QUARITE): A Cluster-Randomised Trial. Lancet, 382, 146-157. https://doi.org/10.1016/S0140-6736(13)60593-0

[22] Faye, A., Fournier, P., Diop, I., Philibert, A., Morestin, F. and Dumont, A. (2013) Developing a Tool Tomeasure Satisfaction among Health Professionals in Sub-Saharan Africa. Human Resources for Health, 11, 30. https://doi.org/10.1186/1478-4491-11-30

[23] Dumont, A., Fournier, P., Fraser, W., Haddad, S., et al. (2009) QUARITE (Quality of Care, Riskmanagement and Technology in Obstetrics): A Cluster-Randomized Trial of a Multifaceted Intervention to Improve Emergency Obstetric Care in Senegal and Mali. Trials, 10, 85. https://doi.org/10.1186/1745-6215-10-85

[24] Faye, A., Dumont, A., Ndiaye, P. and Fournier, P. (2014) Development of an Instrument to Evaluate Intrapartum Care Quality in Senegal: Evaluation Quality Care. International Journal for Quality in Health Care, 26, 184-189. https://doi.org/10.1093/intqhc/mzu018

[25] Wade, G.H. (1999) Professional Nurse Autonomy: Concept Analysis and Application to Nursing Education. Journal of Advanced Nursing, 30, 310-318. https://doi.org/10.1046/j.1365-2648.1999.01083.x

[26] Spector, P.E. (1985) Measurement of Human Service Staff Satisfaction: Development of the 
Job Satisfaction Survey. American Journal of Community Psychology, 13, 693-713. https://doi.org/10.1007/BF00929796

[27] Shah, A., Faundes, A. and Machoki, M.E.A. (2008) Methodological Considerations in Implementing the WHO Global Survey for Monitoring Maternal and Perinatal Health. Bulletin of the World Health Organization, 78, 126-131. https://doi.org/10.2471/BLT.06.039842

[28] English, M., Nzinga, J., Mbindyo, P., Ayieko, P., Irimu, G. and Mbaabu, L. (2011) Explaining the Effects of Amultifaceted Intervention to Improve Inpatient Care in Rural Kenyan Hospitals-Interpretation Based on Retrospective Examination of Data from Participant Observation, Quantitative and Qualitative Studies. Implementation Science, 6, 124. https://doi.org/10.1186/1748-5908-6-124

[29] Willis-Shattuck, M., Bidwell, P., Thomas, S., Wyness, L., Blaauw, D. and Ditlopo, P. (2008) Motivation and Retention of Health Workers in Developing Countries: A Systematic Review. BMC Health Services Research, 8, 247. https://doi.org/10.1186/1472-6963-8-247

[30] Pillay, R. (2009) Work Satisfaction of Professional Nurses in South Africa: A Comparative Analysis of the Public and Private Sectors. Human Ressources for Helath, 7, 15. https://doi.org/10.1186/1478-4491-7-15

[31] Dieleman, M., Toonen, J., Touré, H. and Martineau, T. (2006) The Match between Motivation and Performance Management of Health Sector Workers in Mali. Human Resources for Helath, 4, 2. https://doi.org/10.1186/1478-4491-4-2

[32] Ministère de la Sante (2012) Projet de financement basé sur les résultats [Project Based on Results]. 50 p.

[33] Humphrey, S.E., Nahrgang, J.D. and Morgeson, F.P. (2007) Integrating Motivational, Social and Contextual Work Design Features: A Meta-Analytic Summary and Theoretical Extension of the Work. Journal of Applied Psychology, 92, 1332-1336. https://doi.org/10.1037/0021-9010.92.5.1332

[34] McGregor, D. (1960) The Human Side of Enterprise. McGraw-Hill, New York.

[35] Marinucci, F., Majigo, M., Wattleworth, M., Paterniti, A.D., Hossain, M.B. and Redfield, R. (2013) Factors Affecting Job Satisfaction and Retention of Medical Laboratory Professionals in Seven Countries of Sub-Saharan Africa. Human Ressources for Helath, 11, 38. https://doi.org/10.1186/1478-4491-11-38

[36] Oyeyemi, A.Y., Oyeyemi, A.L., Maduagwu, S.M., Rufai, A.A. and Aliyu, S.U. (2012) Professional Satisfaction and Desire to Emigrate among Nigerian Physiotherapists. Physiotherapy Canada, 64, 225-232. https://doi.org/10.3138/ptc.2010-45

[37] McAuliffe, E., Manafa, O., Maseko, F., Bowie, C. and White, E. (2009) Understanding Job Satisfaction amongst Mid-Level Cadres in Malawi: The Contribution of Organisational Justice. Reproductive Health Matters, 17, 80-90. https://doi.org/10.1016/S0968-8080(09)33443-6

[38] Ridde, V. and Samb, O. (2010) La place de l'équité dans la formation des professionnels de santé au Burkina-Faso [The Role of Equity in the Training of Health Professionals in Burkina Faso]. Dans, H.S.Yaya (dir), Les mots et les choses de la santé [The Words and Things of Health]. Acteurs, pratiqueset systèmes de santé dans le tiers-monde [Actors, Practices and Health Systems in the Third World]. Québec, Presses de l'Université Laval, 93-120.

[39] Leonard, K.L. and Masatu, M.C. (2007) Using the Hawthorne Effect to Examine the Gap between Adoctor's Best Possible Practice and Actual Performance. Journal of Development Economics, 93, 226-234. https://doi.org/10.1016/j.jdeveco.2009.11.001 
Submit or recommend next manuscript to SCIRP and we will provide best service for you:

Accepting pre-submission inquiries through Email, Facebook, LinkedIn, Twitter, etc. A wide selection of journals (inclusive of 9 subjects, more than 200 journals)

Providing 24-hour high-quality service

User-friendly online submission system

Fair and swift peer-review system

Efficient typesetting and proofreading procedure

Display of the result of downloads and visits, as well as the number of cited articles Maximum dissemination of your research work

Submit your manuscript at: http://papersubmission.scirp.org/

Or contact ojog@scirp.org 